\title{
An Integrated Knowledge Base System Architecture for Histopathological Diagnosis of Breast Diseases
}

\author{
Aderonke A. Kayode \\ Department of Computer Science \& Engineering, Obafemi Awolowo University, Ile-Ife, Nigeria \\ kayodeaa_1@yahoo.com, \\ Babajide S.Afolabi \\ Department of Computer Science \& Engineering, Obafemi Awolowo University, Ile-Ife, Nigeria \\ bafox@oauife.edu.ng \\ Kayode A. Adelusola \\ Department of Morbid Anatomy, Obafemi Awolowo University, Ile-Ife, Nigeria \\ kadelman02@yahoo.com
}

\begin{abstract}
The histopathological diagnosis of breast diseases requires highly trained and experienced experts, and often strains pathologists' cognitive capabilities. Accurate and timely diagnosis of breast diseases is essential for the appropriate management of the patients.
\end{abstract}

The paper presents a knowledge base system that uses a combination of rule-based and case-based techniques to achieve the diagnosis. Rule-based systems handle problems with well-defined knowledge bases this limits the flexibility of such system. Casebased reasoning has been adopted to overcome this inherent weakness of rule-based systems by incorporating previous cases in the generation of new cases to improve the performance of the system. The result of this research shows that the system is capable of assisting pathologists in making accurate, consistent and timely diagnoses. The system also aid in eliminating errors of omission that have been viewed as a prominent cause of medical errors. In conclusion this paper investigated the histological features used in the diagnosis of breast diseases and proposed an integrated knowledge base system based on the features.

Index Terms - Knowledge Base Systems, Case-Based Reasoning, Rule-Based Reasoning, Artificial Intelligence, Diagnosis

\section{Introduction}

Integrating computer technology and artificial intelligence is a promising approach in the provision of quality health delivery services in medicine. Artificial intelligence (AI) is a branch of computer science concerned with the design and implementation of programs which are capable of emulating human thinking skills, such as problem solving, visual perception and language understanding. It is concerned with the creation of computer programs to perform activities which, if performed by a person, would require intelligence.

Artificial Intelligence in Medicine (AIM) as a field emerged in the early 1970's in response to several simultaneous needs, opportunities, and interests ${ }^{[1]}$. An increased demand for high-quality medical services coupled with the explosive growth of medical knowledge has led to the suggestion that computer programs could be used to assist physicians and other health care providers in discharging their clinical roles in diagnosis, therapy and prognosis ${ }^{[2]}$.

One of the first uses of AI on a practical level was the coupling of expert medical knowledge with computer-based technology. As early as the 1960s, computer scientists and physicians recognized the possibility that computers could assist doctors in the diagnosis and treatment of diseases ${ }^{[3]}$.

The field of AI includes the areas of natural language processing, robotics, machine vision and expert systems ${ }^{[4]}$.

An Expert System (ES), sometimes called a Knowledge Base System (KBS) is a computer program that contains some of the subject specific knowledge of one or more human experts. ES automates expert's tasks, which require specialized skills and training. Examples of these tasks include medical diagnosis, equipment repair, computer configuration and financial planning ${ }^{[5]}$. 
The aim of this study is to design an integrated knowledge-based system, which is capable of making use of heuristic knowledge and previous cases to improve its performance. The idea is to use rule-based reasoning to generate a diagnosis for Histopathological Breast Diseases (HBD) and to use case-based reasoning to handle exceptions to the rules. A characteristic of a rule-based system is handling problems from a well-defined knowledge base that contains rules. In an only partially-understood domain, this approach may become impractical. Therefore one approach for improving rule-based systems is to extend the rule set by integrating the rule-based system with a case-based reasoning system. A case-based reasoning system is used to solve problems by incorporating past experiences in a partially-understood domain.

The remainder of this paper is organized as follows: Section 2, 3 and 4 describe the rule base reasoning, the case base reasoning and object oriented design respectively. Section 5 presents the related works on automatic diagnosis of breast diseases, section 6 discusses method used, section 7 explains the result of the integrated architecture for HDBD. Conclusion is given in section 8 .

\section{Rule-based Systems}

The idea of rule-based systems is to represent a domain expert's knowledge in a form called rules ${ }^{[6]}$. In a typical rule-based expert system, a rule consists of several premises and a conclusion. If all the premises are true, then the conclusion is considered true. That is, a rule consists of two parts: condition (antecedent) part and conclusion (action, consequent) part, i.e.: IF (conditions) THEN (actions).

Figure 1 below illustrates the components of a rulebased system.

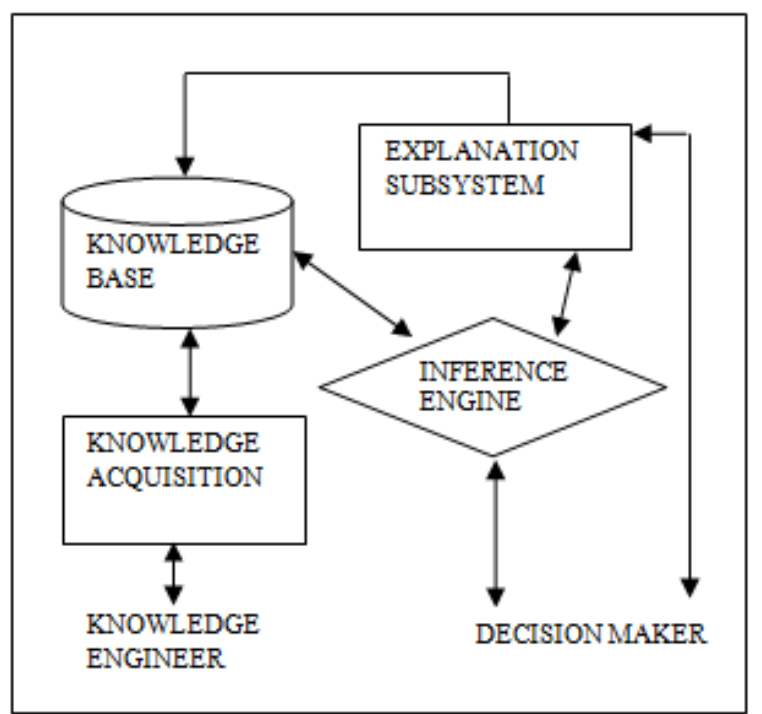

Fig. 1: General structure of an expert system
Knowledge base. The permanent knowledge of an expert system is stored in a knowledge base. It contains the information that the expert system uses to make decisions. This information presents expertise gained from top experts in the field. This knowledge comes in the form of facts and rules. Facts are minimal elements of the knowledge which must be identified before anything else. For example, 'fibroadenoma is a breast disease' is a fact.

Rules consist of 'if...then' statements, where a given set of conditions will lead to a specified set of results.

Inference Engine. The inference engine is a computer program that controls the execution, and uses rules to respond to a query and determine whether a suitable match can be found in the fact list, through backward or forward chaining. It determines which rules will be applied to a given question and in what order by using information in the knowledge base.

Backward- and/or forward-chaining reasoning models are typically implemented in rule-based expert systems: Backward chaining is an approach that starts with a goal, e.g., "Which HBD is it?" and works through a potential thesis until it reaches the fact that supports the thesis.

Forward-chaining inference engines are goaloriented in the sense that they try to prove a goal or rule conclusion by confirming the truth of all the premises. These premises may themselves be conclusions of other rules. This method begins with a set of known facts or attributes values, and applies these values to rules that use them in their premise.

Knowledge Acquisition. Most expert systems continue to evolve over time. New rules can be added to the knowledge base by using the knowledge acquisition sub-system.

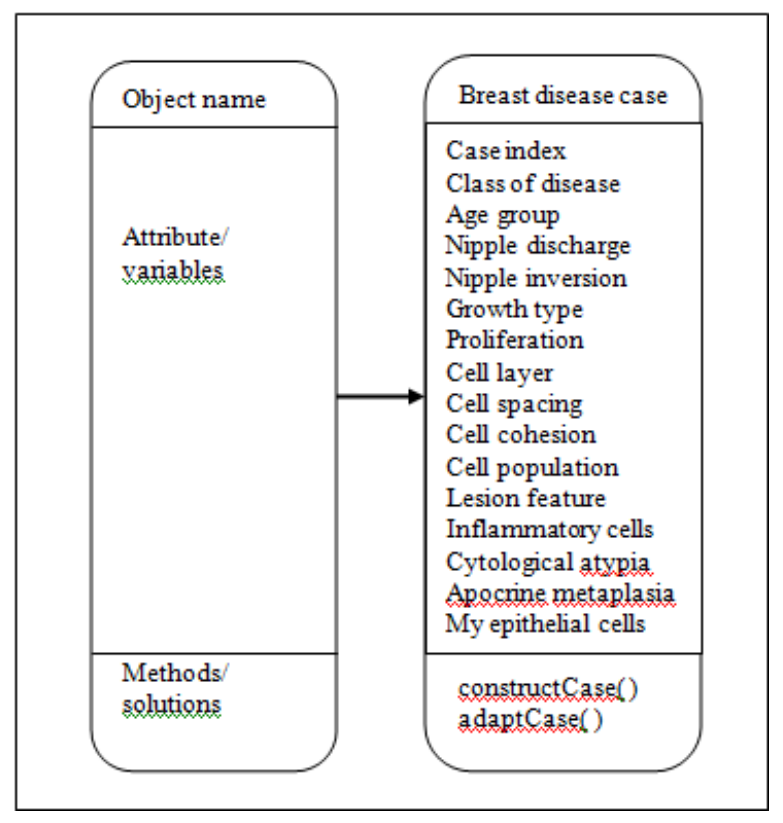

Fig. 2: Structure of Objects 


\section{Case Based Reasoning}

According to ${ }^{[7]}, \mathrm{CBR}$ is a problem solving technique which complements the solution, acting as a memory of past cases which can be consulted in order to identify similar cases for the new problem. CBR is described as a cyclical process comprising of the four 'Re's ${ }^{[8]}$. These are: (1) retrieve the most similar case, (2) re-use the case to attempt to solve the problem, (3) revise the proposed solution if necessary and (4) retain the solution as part of the new case.

CBR is an approach to incremental sustained learning, since a new experience is retained each time a problem has been solved. After identifying a given breast disease, an expert is reminded of an other disease that he had come across some time ago. Assuming that the reminding was caused by a similarity of important characteristics, the expert uses the diagnosis to the previous disease to determine the disease at hand.

A CBR works in much the same manner as our memories. We learn new things, we learn more about old things, and we retain and reuse new information. It will differ from logic or rules based engine in aspects of recording and retrieving cases.

A case is a contextualised piece of knowledge representing an experience. It contains a past lesson, that is, the content of the case and the context in which the lesson can be used ${ }^{[9]}$. Typically a case comprises: the problem, the solution to the problem, and the outcome after the solution has been applied to the problem.

In a case-based system, a problem is matched against cases in the case base, and one or more similar cases are retrieved. Case indexing [10] involves assigning indices to cases to facilitate their retrieval. A solution suggested by the matching cases is then reused. Unless the retrieved case is a close match, the solution will probably have to be revised, producing a new case that can be retained. For example if the past experience was a disease called intraductal papilloma, and the disease that is current is a multiple papilloma, that means the case that is nearest to the new disease is intraductal papilloma, and hence the revised content will have the characteristics of the intraductal papilloma as the base, as well as the additional characteristics that are peculiar to multiple papilloma. Therefore inductive indexing is basically a search for similarities among a series of instance and categorization based on these similarities.

The components of a case-based system are the input module, the case memory, retriever, the case adapter and a module to update cases.

Input module. The input module takes new cases. The case is forwarded to the indexing/matching module.

The case memory. The cases are stored in the case memory and may be represented as objects. The case memory is a hierarchy of objects. Any real world entity is uniformly modeled as an object. Every object is an entity that has a state, that is, the set of values for the attributes of the object; and behaviour, that is, a set of methods which operate on the state of the object. The object-oriented paradigm is based on encapsulating the variables and the methods that operate on them into a single object. Conceptually, all interactions between an object and the rest of the system are via messages. Thus, the interface between an object and the rest of the systemis defined by a set of allowed messages.

In CBR, the object attributes represent the internal characteristics of an object that facilitate the complete description of the case, and can be used to retrieve, reuse and interpret the case. The list includes attributes needed for classifying and indexing cases, attributes needed for interpreting the cases, attributes serving as the basis for decision-making and performance evaluation and attributes related to recognisable changes in scenarios that can be reused by others. Figure 2 is an example of an object on a breast disease.

Retriever. In its most basic form, the case retrieval procedure consists of searching the case base to find historical cases that most closely resemble the current problem. The comparison consists of matching attributes of the current problem with those of each historical case.

Case adaptation. It is possible that the most similar case in the case base is significantly different from the current problem. Alternatively, there may be subtle but critical differences between them that invalidate the application of the old solution to the current problem. In such cases, it may be necessary to modify the his torical solution to fit the current problem.

Case update. Once the current problem has been solved through the retrieval and adaptation of a historical case, the current case can be integrated into the case base as a new historical.

Following are the advantages of CBR:

1. The problem of the knowledge-elicitation bottleneck is surpassed, since elicitation is a simpler way of acquiring past cases.

2. CBR systems can propose a solution quickly.

3. CBR systems can learn by acquiring new cases, making maintenance easier to demonstrate.

4. Unlike RBR systems, CBR systems can grow to reflect their organisation's experience by acquiring new episodic cases.

\section{Object-oriented Design}

The object oriented paradigm is well-covered in literature ${ }^{[11]}$ and ${ }^{[12]}$. Objects are autonomous entities that have a state and respond to messages. All objects communicate using the same mechanism of message passing, and the processing activity takes place inside the objects. Inheritance allows the classification of ob 
jects which permits their properties to be shared [13][14][15]

Abstraction in terms of object-oriented concepts is a technique that involves the selective examination of certain aspects of an application. It has the goal of isolating those aspects that are important for an understanding of the application, and suppressing those aspects that are irrelevant. Forming an abstraction in terms of classes and objects is one of the fundamental tenets of the object-oriented paradigm.

Re-using already available software components facilitates rapid software development and promotes the production of additional components. Taking components created by others is better than creating new ones. If a good library of re-usable components exists, browsing components to identify opportunities for re-use should take precedence over writing new ones from scratch.

Inheritance is an object-oriented technique that boosts re-usability ${ }^{[16]}$ and ${ }^{[17]}$.

\section{Related Works}

Many publications have covered the development of knowledge-based systems using case-based reasoning in the areas of conceptual design ${ }^{[18]}$, aircraft conflict resolution ${ }^{[19]}$, military decision support systems ${ }^{[20]}$, helpdesk operations ${ }^{[21]}$, customer service management ${ }^{[22]}$, legal systems ${ }^{[23]}$ and ${ }^{[24]}$, diagnosis ${ }^{[25]}$, design ${ }^{[26]}$ and planning ${ }^{[27]}$. It is seen that the applications of CBR in developing knowledge-based systems have been widely adopted in various industries and areas.

There are a number of expert systems that have been developed using rule-based reasoning. This covers areas such as mining ${ }^{[28]}$, commerce ${ }^{[29]}$, diagnos is ${ }^{[30]}$, medicine ${ }^{[31]}$, and robotics ${ }^{[32]}$.

Also, the use of expert systems in the diagnoses of breast cancers is not new, the earliest study encountered was by Cook and Fox [33], where mammographic image analysis was investigated using a decision table to represent all the parameters and possibilities in 41 rules that were created, all centered upon masses and lesions. The other related works were mostly based on Artificial Neural Networks (ANN) for decision making in the diagnoses of breast cancer and some of the work are related to breast mammographic decisions ${ }^{([34]},{ }^{[35]},{ }^{[36]},{ }^{[37]},{ }^{[38]}$ and ${ }^{[39])}$

In the like manner ${ }^{[40]}$ proposed an artificial intelligent algorithm for tumor detection in screening mammogram; [41] proposed a multiple circular path convolution neural network system for detection of mammographic masses; ${ }^{42]}$ classified mammographic breast density using a comb ined classifier paradig $\mathrm{m}$, ${ }^{[43]}$ worked on the automatic classification of mammography parenchyma patterns in breast cancer; ${ }^{[44]}$ presented an automatic mammographic diagnosis system for detecting breast cancer based on association rules (AR) and neural network (NN) and ${ }^{[45]}$ worked on frame- based decision support system for histopathological diagnosis of breast diseases in women.

\section{Method}

An initial familiarization with the subject of histological diagnosis was carried out through the study of the standard breast pathology textbooks. Journals were also used to obtain detailed information in specific areas.

Further investigation was carried out through interviews with a participating pathologist. These allowed specific diagnostic points to be clarified and potentially problematic areas of diagnosis to be identified. Such interviews have continued regularly throughout the duration of this study, providing valuable feedback. There are several important items of diagnostic knowledge that are used by all pathologists in the identification of histological types. These include information about the possible clinical symptoms of a disease, its rate of occurrence, and microscopic characteristics.

Detailed discussions were held from time to time with the consultant pathologist to ensure that the work progresses in an acceptable frame of reference. Finally, the characteristics contained in the table1 were obtained with the consensus of the pathologists.

\subsection{Knowledge Elicitation (KE)}

The method used for Knowledge Elicitation in this study is interview method. This stage, involved interviews held with the expert, a pathologist specialized in breast diseases, where several aspects of the problem were discussed. Furthermore, a broad bibliographical material on breast diseases was covered by the knowledge engineer, in order a) to acquire background knowledge on the subject, so that the engineer could go along with the pathologist, and b) to obliterate the subjectivity of the single expert.

During the early stages of the knowledge acquisition, materials of a general nature were also covered. The objective was to uncover key concepts and general problem-solving methods used by the expert in the his topathologicaldiagnosis of breast diseases.

The knowledge acquired from the domain experts is presented in table 1which shows the clinical and microscopic features used by pathologists in diagnosing breast diseases. These characteristics underwent numerous changes until the consultant pathologist was satisfied. 
Table 1: Features used in HDBD

\begin{tabular}{ll}
\hline \multicolumn{1}{c}{ Features } & Possible Outcomes \\
\hline Age group & Pre-menopausal, menopausal, post menopausal, not applicable \\
Nipple discharge & watery, cloudy, bloody \\
Nipple inversion & yes, no, not applicable \\
Lesion class & benign, malignant \\
Growth type & infiltrating, non -infiltrating \\
Proliferation & stromal, epithelial \\
Cell layer & double, multiple \\
Cell spacing & regular, irregular, not applicable \\
Cell cohesion & tightly, loosely \\
Cell population & Monomorphic (complete, incomplete), pleomorphic \\
Lesion feature & necrosis, hemorrhage, not applicable \\
Inflammatory cells & present, absent, not applicable \\
Cytological atypia & yes, no, not applicable \\
Apocrine metaplasia & present, absent, not applicable \\
Myoepithelial cells & present, absent, not applicable \\
\hline
\end{tabular}

Note: when diagnosing a disease, the outcome of a feature is tagged 'not applicable' when that feature is not a diagnosticfa ctor in the differential diagnosis of such disease.

\subsection{The Rule-Based Expert System Components for HDBD}

The facts in the knowledge base of the rule-based expert system include breast diseases, their class, the clinical and histological characteristics of each of the breast diseases etc.

Knowledge is represented in the form of rules as shown in table 2

Table 2: Sample IF - THEN Rules obtained from the knowledge elicited

\begin{tabular}{|c|c|c|c|}
\hline S/No & Antecedence & Status & Consequence \\
\hline 1. & $\begin{array}{l}\text { Pre-menopausal } \\
\text { Benign lesion } \\
\text { Non-infiltrating growth } \\
\text { Double cell layer } \\
\text { Apocrine metaplasia. }\end{array}$ & $\begin{array}{l}\text { TRUE } \\
\text { TRUE } \\
\text { TRUE } \\
\text { TRUE } \\
\text { TRUE }\end{array}$ & FIBROADENOMA \\
\hline 2. & $\begin{array}{l}\text { Benign lesion } \\
\text { Epithelial proliferation } \\
\text { Non-infiltrating growth } \\
\text { Multiple cell layer } \\
\text { Myoepithelial cells }\end{array}$ & $\begin{array}{l}\text { TRUE } \\
\text { TRUE } \\
\text { TRUE } \\
\text { TRUE } \\
\text { TRUE }\end{array}$ & EPIT HELIAL HYPERPLASIA \\
\hline 3. & $\begin{array}{l}\text { Bloody discharge } \\
\text { Benign lesion } \\
\text { Epithelial proliferation } \\
\text { Non-infiltrating growth } \\
\text { Double cell layer } \\
\text { Myoepithelial cells } \\
\text { Hemorrhage. }\end{array}$ & $\begin{array}{l}\text { TRUE } \\
\text { TRUE } \\
\text { TRUE } \\
\text { TRUE } \\
\text { TRUE } \\
\text { TRUE } \\
\text { TRUE }\end{array}$ & SCLEROSING ADENOSIS \\
\hline 4. & $\begin{array}{l}\text { Pre-menopausal } \\
\text { Bloody discharge } \\
\text { Benign lesion } \\
\text { Epithelial proliferation } \\
\text { Non-infiltrating growth } \\
\text { Double cell layer } \\
\text { Myoepithelial cells } \\
\text { Necrosis }\end{array}$ & $\begin{array}{l}\text { TRUE } \\
\text { TRUE } \\
\text { TRUE } \\
\text { TRUE } \\
\text { TRUE } \\
\text { TRUE } \\
\text { TRUE } \\
\text { TRUE }\end{array}$ & INTRADUCTAL PAPILLOMA \\
\hline 5. & $\begin{array}{l}\text { Post-menopausal } \\
\text { Malignant } \\
\text { Epithelial proliferation } \\
\text { Non-infiltrating growth Myoepithelial cells } \\
\text { Pleomorphic } \\
\text { Tight cohesion } \\
\text { periductal fibrosis } \\
\text { Necrosis. }\end{array}$ & $\begin{array}{l}\text { TRUE } \\
\text { TRUE } \\
\text { TRUE } \\
\text { TRUE } \\
\text { TRUE } \\
\text { TRUE } \\
\text { TRUE } \\
\text { TRUE } \\
\text { TRUE }\end{array}$ & COMEDO CARCINOMA \\
\hline
\end{tabular}




\subsection{The case-based expert system components for HDBD}

Let us consider the example of the INTRADUCTAL PAPILLOMA and SCLEROSING ADENOSIS diseases of the breast. Except for the differences in the lesion feature of the diseases, the rest of the characteristics are similar. Supposing that the rulebased expert system has captured only INTRADUCTAL PAPILLOMA, then if the disease detected proves to be SCLEROSING ADENOSIS that would mean that its characteristics have to be captured in the case-based reasoning expert system. SCLEROSING ADENOSIS will inherit the characteristics of the INTRADUCTAL PAPILLOMA, and in addition, the lesion feature is modified. To represent the inheritance in object- oriented terms.

In Figure 5, the rectangle represents the inheritance. This means that SCLEROSING ADENOSIS object will inherit all the characteristics of the INTRADUCTAL PAPILLOMA and will additionally have a method to reset the lesion feature of the disease, resulting in the SCLEROSING ADENOSIS.

\subsection{The Integrated Architecture}

The architectural goal is to improve rule-based reasoning by augmenting it with case-based reasoning.
This augmentation is done by taking the rules as a starting point of problem-solving, i.e. using rules to generate a first approximation to the diagnosis for a target disease and then invoking case-based reasoning to handle exceptions to the rules.

The idea is to fine-tune the performance of the rules. Another advantage is that if the case-based reasoning misses a similar case, the architecture will at least have a reasonable default answer generated by the rulebased system.

The architecture of the integrated expert system is shown in Figure 3, while the flow in the system is as shown in Figure 4. Each subsystem is essentially an individual problem solver. If a case-based solution is available, case-based reasoning can learn by acquiring new knowledge. The input uses disease characteristics and produces a casual network of possible diagnosis that lead to those diseases. When a disease arises, the system tries to find diseases with similar, but not identical, properties. The system adapts the diagnosis by considering the differences in characteristics between the old and new cases. The component to add a new case is generated.

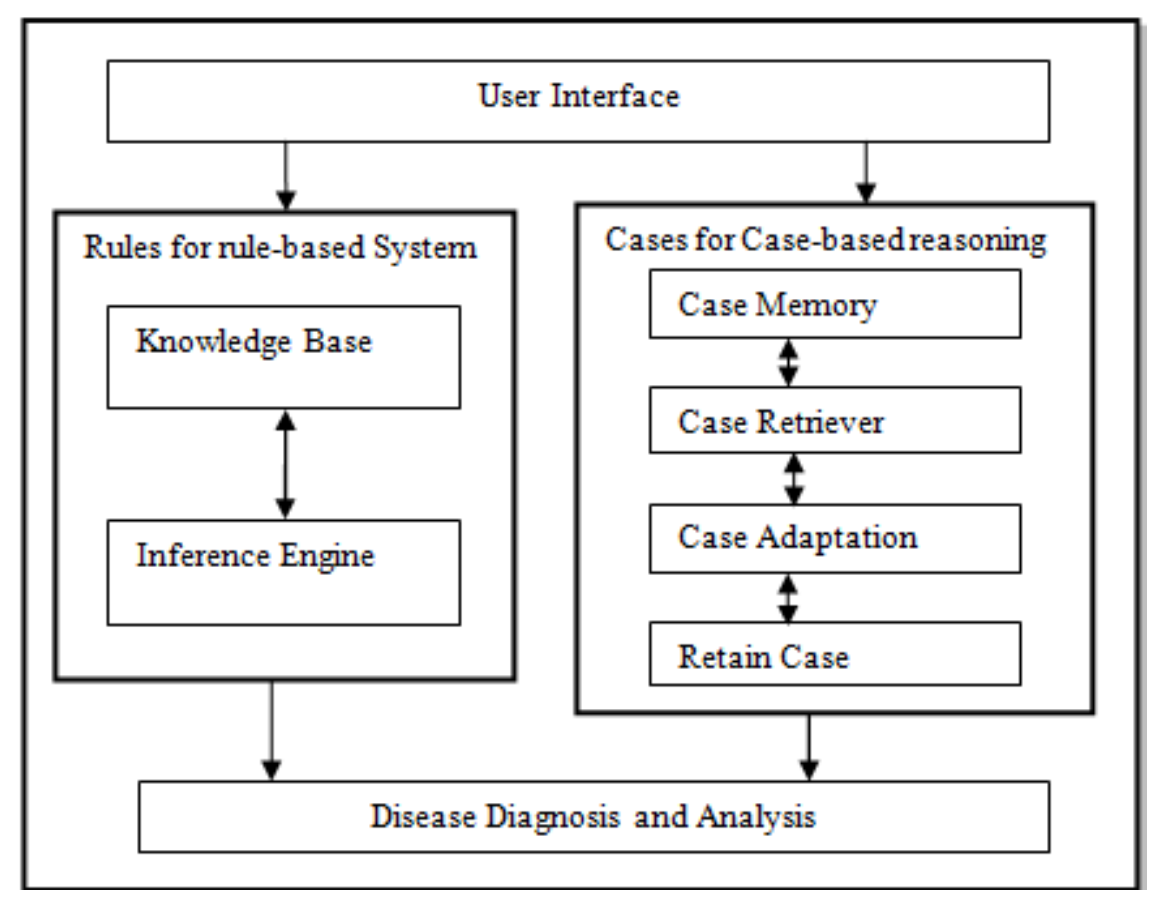

Fig. 3: Integrated architecture for HDBD 


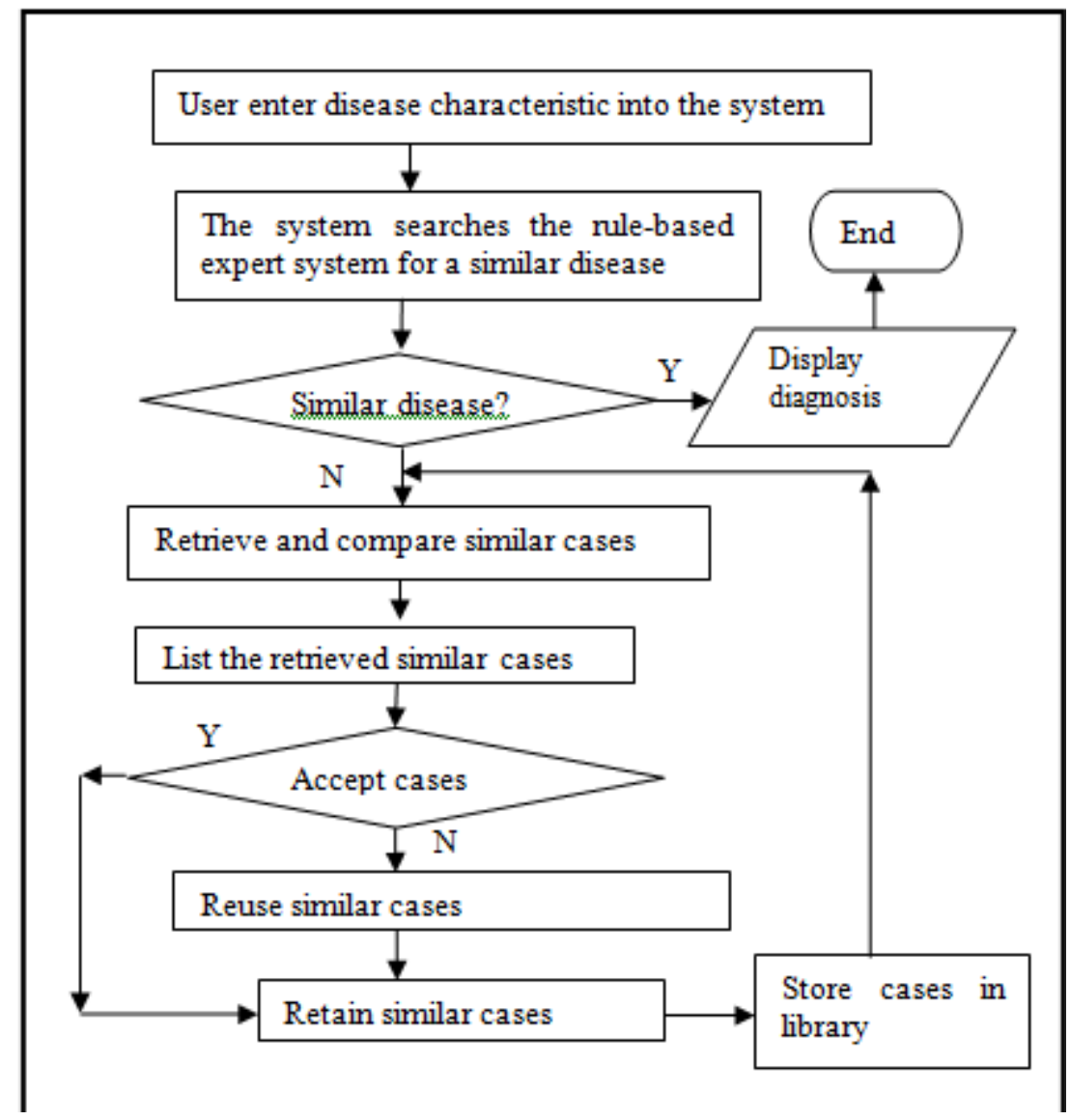

Fig. 4: Flow of data in the integrated architecture for HDBD

\section{Result and Discussion}

The system was tested using two set of samples: the first comprising 10 retrospective samples (table 3 , appendix section) of breast disease in the form of slide preparations obtained from the Department of Morbid Anatomy, Obafemi Awolowo Teaching Hospital, IleIfe, Nigeria. The second consisting five hypothetical cases of breast diseases (table 4, appendix section) which were included to represent interesting and demanding diagnostic areas in which the consultant pathologist wished to explore the system's behavior.

The aim of this evaluation was to determine if the system can assist an inexperience pathologist in making accurate, consistent and timely diagnoses.

A consultant pathologist evaluated the system's recommendation which was summarized in table in the appendix section. The diagnoses made by the system were classified by the consultant pathologist into one of three categories:



Fig. 5: Inheritance in objects. 
1. Correct: The system's recommendation was identical with the pathologist's own diagnosis.

2. Acceptable: The system's recommendation was different from that of the pathologist, but considered an acceptable alternative.
3. Incorrect: The system's recommendation was different from that of the pathologist and not an acceptable alternative i.e. contradictory to "gold standard" diagnos is of the consultant pathologist.

Table 3: System's performance using retrospective of breast disease

\begin{tabular}{|c|c|c|c|c|c|}
\hline Case No & $\begin{array}{l}\text { Differential } \\
\text { problem }\end{array}$ & $\begin{array}{c}\text { Pathologist's } \\
\text { Recommendation }\end{array}$ & $\begin{array}{c}\text { System's } \\
\text { Recommendation }\end{array}$ & No of question & Evaluation \\
\hline 1. & $\begin{array}{l}\text { Epithelial Hyperplasia } \\
\text { atypical ductal hyperplasia } \\
\text { atypical lobular hyperplasia }\end{array}$ & EpithelialHyperplasia & Epithelial Hyperplasia & 7 & Correct \\
\hline 2. & $\begin{array}{l}\text { Duct ectasia } \\
\text { Fibrocytic change }\end{array}$ & Duct ectasia & Duct ectasia & 5 & Correct \\
\hline 3. & Unknown & $\begin{array}{l}\text { Atypical Ductal } \\
\text { Hhyperplasia }\end{array}$ & Atypical Ductal Hyperplasia & 6 & Correct \\
\hline 4. & $\begin{array}{l}\text { Multiple papilloma } \\
\text { Intraduct al papilloma } \\
\text { Papillary carcinoma in situ }\end{array}$ & Intraductal papilloma & Intraductal papilloma & 6 & Correct \\
\hline 5. & $\begin{array}{l}\text { Cribriform carcinoma } \\
\text { Comedo carcinoma } \\
\text { Papillary carcinoma in situ }\end{array}$ & Comedo carcinoma & $\begin{array}{l}\text { Comedo carcinoma } \\
\text { Cribriform carcinoma }\end{array}$ & 8 & acceptable \\
\hline 6. & $\begin{array}{l}\text { atypical ductal hyperplasia } \\
\text { Lobular carcinoma in situ } \\
\text { atypical lobular hyperplasia }\end{array}$ & Lobular carcinoma in situ & Lobular carcinoma in situ & 6 & Correct \\
\hline 7. & $\begin{array}{l}\text { Complex Sclerosing lesion } \\
\text { Sclerosing adenosis } \\
\text { Intraduct al papilloma }\end{array}$ & Sclerosing adenosis & Sclerosing adenosis & 7 & Correct \\
\hline 8. & $\begin{array}{l}\text { Fibroadenoma } \\
\text { Phyllode tumour }\end{array}$ & Complex fibroadenoma & Complex fibroadenoma & 5 & Correct \\
\hline 9. & $\begin{array}{ll}\text { Fibrocytic } & \text { change } \\
\text { Fibroadenoma } & \end{array}$ & Ffibrocytic change & Fibrocytic change & 5 & Correct \\
\hline 10. & $\begin{array}{l}\text { atypical ductal hyperplasia } \\
\text { Invasive ductal carcinoma } \\
\text { Ductal Carcinoma in situ }\end{array}$ & Medullary carcinoma & Comedo carcinoma & 9 & Incorrect \\
\hline
\end{tabular}

Table 4: System's performance using hypothetical cases of breast disease

\begin{tabular}{|c|l|l|l|c|c|}
\hline Case No & \multicolumn{1}{|c|}{$\begin{array}{c}\text { Differential } \\
\text { problem }\end{array}$} & $\begin{array}{c}\text { Pathologist's } \\
\text { Recommendation }\end{array}$ & $\begin{array}{c}\text { System's } \\
\text { Recommendation }\end{array}$ & No of question & Evaluation \\
\hline 1. & $\begin{array}{l}\text { Epithelialhyperplasia } \\
\text { atypical ductal hyperplasia }\end{array}$ & EpithelialHyperplasia & Epithelialhyperplasia & 5 & Correct \\
\hline 2. & $\begin{array}{l}\text { Fibrocytic change } \\
\text { fibroadenoma }\end{array}$ & fibroadenoma & fibroadenoma & 5 & Correct \\
\hline 3. & $\begin{array}{l}\text { Ductal Carcinoma in situ } \\
\text { atypical ductal hyperplasia } \\
\text { Invasive ductal carcinoma }\end{array}$ & Invasive ductal carcinoma & Invasive ductal carcinoma & 6 & Correct \\
\hline 4. & $\begin{array}{l}\text { papilloma } \\
\text { Papillary carcinoma in situ }\end{array}$ & intraductal papilloma & intraductal papilloma & 5 & Correct \\
\hline 5. & $\begin{array}{l}\text { Cribriform carcinoma } \\
\text { Comedo carcinoma } \\
\text { Papillary carcinoma in situ }\end{array}$ & Comedo carcinoma & Comedo carcinoma & 8 & Correct \\
\hline
\end{tabular}

Testing proceeded in the following manner. The evaluating/consultant pathologist examined the slide (or slides) of each case microscopically, identified the perceived differential problem, if possible, and then used the system to direct data gathering. When all the questions generated by the system had been answered and the diagnosis was made, the pathologist compared the system's recommendations to his own diagnosis and classified it into one of the three categories described above.

From a total of 15 possible correct diagnoses, the system's recommendation was judged "correct" by the pathologist in 13 cases, acceptable in 1 case and incorrect in only 1 case. 


\section{Conclusion}

The knowledge for interpreting slides of diseased breast tissue allows an experienced pathologist specialised in breast pathology to follow a systematic, orderly and logical line of reasoning that leads to a proper diagnosis. This system was developed to simulate the above logical reasoning, in order to facilitate inexperienced pathologists in the histological interpretation of the slides of diseased breasts.

The system's knowledge base has been evaluated positively by an experienced pathologist who is an expert in histopathological interpretation and diagnosis of breast diseases.

Based on the result obtained, the system is capable of assisting an inexperience pathologist to make accurate and timely decision, in the like manner, the system assists an experience pathologist in providing a substantial aid in eliminating the errors of omission that have been viewed as a prominent cause of med ical errors thereby increasing the efficiency of his diagnostic skills. Also, automatic system such as this does not only have a role to play in enhancing decision making but also in the study of diagnostic protocol, education, self-assessment, and quality control in the domain of breast histopathology.

\section{References}

[1] Szolovits. P, Patil RS and Schwartz. WB, "Modeling Knowledge of the Patient in Acid-Base and Electrolyte Disorders" Artificial Intelligence in Medicine), Westview Press, Boulder, Colorado, 1982.

[2] Miller P.L, "Selected Topics in Medical Artificial Intelligence: Computer and Medicine", SpringerVerlag, New York, 1998.

[3] Saritas. I, Allahverdi. N, and Sert. I, "A fuzzy expert system design for diagnosis of prostate cancer", International Conference on Computer and Technologies - 'CompSys Tech' 2003.

[4] Biondo. SJ, "Fundamentals of expert systems technology: principles and concepts", Ablex, Norwood, NJ, ISBN-89391-701, 1990.

[5] Allison. BA, "Experience with the Development and Deployment of Expert Systems in Agriculture", 1998, in proceedings of IAAI-95. San Mateo: AAAI Press,

[6] James PI, "The development and Implementation of Rule-Based Expert Systems", McGraw-Hill International Editions, Computer Science Series, 2000.

[7] Choy. KL, Lee. WB, and Lo V, "Design of casebased intelligent supplier relationship management system - the integration of supplier rating system and product code system", Expert Systems with Applications 2003; 25(1):87-100.

[8] Aamodt. A, and Plaza E, “Case-based reasoning: foundational issues, methodological variations and system approaches, Artificial Intelligence communications (AI Com) 1994; 7(1): 35-59.

[9] David. BS, "Principles for case presentation in a case-biased aiding system for lesson planning", Proceedings of the Workshop on Case-based Reasoning, Madison Hotel, Washington, 8-10 May, 1991.

[10] Birnbaum. L and Collins G, "Remindings and engineering design themes: a case study in indexing vocabulary", Proceedings of the Second Workshop on Case-based Reasoning, Pensacola Beach, Florida, 1989.

[11] Booch. G, "Object-oriented design with applications", Redwood City, California: Benjamin/Cummings, 1991.

[12] Coad. P and Yourdon. E, "Object-oriented analys is", Eaglewood Cliffs, New Jersey, PrenticeHall, 1990.

[13] Pascoe. GA,"Elements of object-oriented programming". Byte 1986; 11(8): 139-144.

[14] Rentsch. T, “Object-oriented programming”, ACM SIGPLAN Notices 1982; 17(9): 51-57.

[15] Robson. D, “Object-oriented software systems", Byte 1981; 6(8): 74-86.

[16] Johnson. RE and Foote. B, "Designing reusable classes. Journal of Object-Oriented Programming 1981; 1(2):22-35.

[17] Micallef. J, “Encapsulation, reusability and extendibility in object-oriented programming languages", Journal of Object-Oriented Programming 1988; 1(1):12-36.

[18] Lee. D and Lee. KH, “An approach to case-based system for conceptual ship design assistant", Expert Systems with Applications 1999; 16(2): 97104.

[19] Cunningham. P and Bonzano. A, "Knowledge engineering issues in developing a case-based reasoning application", Knowledge-based Systems 1999; 12(7): 371-379.

[20] Liao. SH, "Case-based decision-support system: architecture for simulating military command and control", European Journal of Operational Research 2000; 123(3): 558-567.

[21] Chan. CW, Chen. LL and Geng. L, "Knowledge engineering of an intelligent case-based system for help-desk operations", Expert Systems with Applications 2000; 18(2): 125-132, 2000.

[22] Cheung. CF, Lee. W B, Wang. WM, Chu. KF and Chu S, "A multi-perspective knowledge-based 
system for customer-service management', Expert Systems with Applications 2003; 24(4): 457-470.

[23] Ashley. KD, "Arguing by analogy in law: a casebased model", DH. Helaman (eds.), Analogical reasoning: perspectives of artificial intelligence, Cognitive Science and Philosophy. D. Redei, 1988.

[24] Bain. WM, "Case-based reasoning: a computer model of subjective assessment". PhD. Thesis, Yale University, Yale, CT, US, 1986.

[25] Hunt. L, "Case-based diagnosis and repair of software faults", Expert Systems 1997;14(1): 1523.

[26] Hinrichs. TR, "Problem solving in open worlds". Lawrance Erlbaum Associates, 1992.

[27] Goodman. M, "CBR in battle planning”. Proceedings of the American Association for Artificial Intelligence, AAAI-86, August 1986, Philadelphia, PA, US, 1989.

[28] Lau. HCW, Jiang. B, Lee. B and Lau. KH, "Development of an intelligent data mining system for a dispersed manufacturing network", Expert Systems 2001: 18(4):175-185.

[29] Lau. HCW, Choy. KL, Lau. PKH, Tsui. WT and Choy. LC, "An intelligent logistics support system for enhancing the airfreight forwarding business", Expert Systems 2004; 25(5):253-268.

[30] Morpurgo. R, and Mussi. S, "I-DSS: an intelligent diagnostic support system", Expert Systems 2001; 18(1): 43-58.

[31] Xu. L. and Li. LX, “An integrated system applied to epidemic screening', Expert Systems 2000; 17(2): 81-89.

[32] Tunstel. E, Howard. A and Seraji. H, "Rule-based reasoning and neural network perception for safe off-road robot mobility", Expert Systems 2002; 19(4): 191-200.

[33] Cook. HM and Fox. MD, “Artificial Intelligence Applied to Mammographic Image Analysis", Electronic Imaging 1987; 1154-1158.

[34] Wu. Y, Giger. ML, Doi. K, Vyborny. CJ, Schmidt. $\mathrm{R}$ and Metz. CE, "Artificial Neural in Mammography: Application to Decision Making in the Diagnosis of Breast Cancer", Radiology 1993; 187: 81-67.

[35] Floyd. C E, Lo. JY. Yun. AJ, Sullivan. DC and Kornguth. PJ, "Prediction of Breast Cancer Malignancy using an Artificial Neural Network", Cancer 1994; 74(11)

[36] Baker. JA, Kornguth. PJ, Lo. JY, Williford. ME and Floyd. CE, "Breast Cancer Prediction with Artificial Neural Network Based on B-RADS Standardized Lexicon", Radiology 1995; 196: 817-822.
[37] Lo. JY, Baker. JA, Kornguth. PJ, Ig lehart. JD and Floyd. CE, "Predicting Breast Cancer Invasion with Artificial Neural Networks On The Basis of Mammographic Features", Radiology 1999; 203: 159-163.

[38] Chen. DR and Chang. YL, "Computer-aided Diagnosis Applied to US of Solid Breast Nodules by Using Neural Networks", Radiology 1999; 213 : 407-412.

[39] Floyd. CE, Lo. JY and Tourassi. GD, "CaseBased Reasoning Computer Algorithm that Uses Mammographic Findings for Breast Biopsy Decisions", Am. J. of Roentgenol 2000; 175: 1347-1352.

[40] Lei. Z and Andrew. KC, "An artificial intelligent algorithm for tumor detection in screening mammogram", IEEE transactions on medical imaging 2000; 20(7).

[41] Huai. L, Shih-Chung. BL, Yue. W, Lisa. K and Matthew. TF, "A multiple circular path convolution neural network system for detection of mammographic masses, IEEE transactions on medical imaging 2002; 21(2):211-217.

[42] Bovis. K and Singh. S, "Classification of mammographic breast density using a combined classifier paradig m. In Med. Image Underst. Anal. 2002;177-180.

[43] Petroudi. S, Kad ir. T and Brady. M, "Automatic classification of mammography parenchyma patterns: A statistical approach". In IEEE Conf. Eng. Med. Biol. Soc. 2003; 1: 798-801.

[44] Karabatak, M. and Ince, M.C. An expert system for detection of breast cancer based on association rules and neural network. Expert Systems with Applications, 2009; 36: 3465-3469

[45] Kayode. AA, Afolabi. BS, Akhigbe. BI, Udo. IJ and Ominiyi. A, "Decision Support System for Histopathological Diagnosis of Breast Diseases in Women" International Journal of Computer Science Issues 2011; 8(2):501-509.

[46] Patel, V.L., Shortliffe, E.H., Stefanelli, M., Szolovits, P., Berthold, M.R. and Bellazzi, R. The coming of age of artificial intelligence in medicine. Artif.Intell.Med 2008; 37: 22-31

\section{Author Profile}

Aderonke A. Kayode holds both B.Sc and M. Sc. in Computer Science She is a member of Information Storage and Retrieval Systems Research Group in the Department of Computer Science and Engineering, Obafemi Awolowo University, Ile-Ife, Nigeria. 
Babajide S. Afolabi is a Senior Lecturer in the Department of Computer Science and Engineering, Obafemi Awolowo University, Ile-Ife, Nigeria and head of the Information Storage and Retrieval Group.

Kayode A. Adelusola is a Professor of pathology in the Obafe mi Awolowo University, Ile-Ife. Nigeria. He is a consultant pathologist in Obafemi Awolowo University Teaching Hospital Complex, Ile- Ife, Nigeria. He authored many articles both within and outside Nigeria.

How to cite this paper: Aderonke A. Kayode, Babajide S.Afolabi, Kayode A. Adelusola,"An Integrated Knowledge Base System Architecture for Histopathological Diagnosis of Breast Diseases", International Journal of Information Technology and Computer Science(IJITCS), vol.5, no.1, pp.74-84, 2013.DOI: 10.5815/ijitcs.2013.01.08 